\title{
CONTROLE ESTRUTURAL DA REDE DE DRENAGEM COM BASE NA CORRELAÇÃO DE DADOS MORFOMÉTRICOS E MORFOESTRUTURAIS: O CASO DA BACIA DO RIBEIRÃO SÃO PEDRO - PARANÁ

\author{
STRUCTURAL CONTROL OF DRAINAGE NETWORK \\ BASED ON CORRELATION OF MORPHOMETRIC AND \\ MORPHOSTRUCTURAL DATA: THE CASE OF SAO PEDRO \\ CREEK BASIN - STATE OF PARANÁ
}

Bruno Aurélio Camolezi
Programa de Pós-graduação em Geografia - Universidade Estadual de Maringá - Av. Colombo, 5.790, Bloco H-12, Sala
18, Zona 7 - MaringálPR - Brasil - e-mail: b.camolezi@gmail.com
Edison Fortes
Programa de Pós-graduação em Geografia- Universidade Estadual de Maringá - Av. Colombo, 5.790, Bloco J-12, Sala
18, Zona 7 - Maringá/PR - Brasil - e-mail: edison-fortes@hotmail.com
Daiany Duarte Manieri
Programa de Pós-graduação em Geografia - Universidade Federal do Paraná - Av. Cel. Francisco H. dos Santos, 100 -
Bloco 5, Sala PH17 - Centro Politécnico - Curitiba/PR, Brasil - e-mal: daiany.manieri@gmail.com

Informações sobre o Artigo

Data de Recebimento:

$14 / 02 / 2012$

Data de Aprovação:

22/06/2012

Palavras-chave:

controle estrutural da rede de drenagem; dados morfoestruturais; dados morfométricos.

\section{Keywords:}

structural control of drainage network; morphostructural data; morphometric data.

\begin{abstract}
Resumo
Os métodos de análise morfoestrutural, baseados em índices morfométricos, constituemse em ferramentas importantes para avaliação do comportamento tectono-estrutural dos sistemas hidrográficos, além de serem métodos baratos e rápidos de levantamento de informações passíveis de correlação com dados de campo. Dessa forma, este artigo teve o objetivo de correlacionar dados morfométricos obtidos a partir do índice de Relação Declividade-Extensão (RDE), Fator de Assimetria de Bacias (FAB) e Fator de Simetria Topográfica Transversal (FSTT), com dados morfoestruturais levantados em escala de detalhe a partir de fotointerpretação geomorfológica. $O$ índice de RDE apresentou 9 trechos com anomalias de segunda ordem e 9 com anomalias de primeira ordem; o índice FAB apresentou um valor de 44, que indica um provável basculamento para a margem direita da bacia e o FSTT apresentou um valor médio de 0,25 , chegando em alguns setores a 0,89 . Esses resultados apresentaram relação entre si, indicando um número maior de anomalias no setor centro-oeste da bacia, o que evidencia controle estrutural da rede de drenagem e das escarpas associadas.
\end{abstract}

\footnotetext{
Abstract

The morphostructural analysis methods, based on morphometric indices constitute important tools for evaluating the tectonic-structural behavior of hydrographic systems,
} 
besides being cheap and quick methods of collecting information, passable to correlate with field data. Thus, this paper is aimed to correlate morphometric data obtained from the Stream Length Index, Asymmetry Factor and Drainage Basin Symmetry, with morphostructural data collected in a detail scale from geomorphologic photointerpretation. The Stream Length Index presented nine sections with second-order anomalies and 9 with first-order anomalies, the Asymmetry Factor Index showed a value of 44, indicating a probable tilting to the right edge of the basin and the Drainage Basin Symmetry had an average value of 0.25 , and in some sectors of 0.89 . These results showed a relation between them, indicating a greater number of anomalies in the central-western sector of the basin, suggesting structural control of drainage network and associated escarpments.

\section{Introdução}

A rede de drenagem é um importante elemento geomorfológico, pois sua arquitetura e geometria podem dar subsídios ao entendimento da evolução geomorfológica de determinada área, visto que a mesma é sensível às alterações crustais recentes, mesmo que pequenas em escala e magnitude (SCHUMM, 1993). A drenagem constitui o primeiro elemento a dar uma resposta àquelas alterações, as quais, por meio de análises da sua configuração, suas formas, associadas à assimetria de vales e controle deposicional, sugerem tais mudanças de base (HOWARD, 1967; ETCHEBEHERE, 2000; SCHUMM et al., 2000).

Além disso, os padrões de drenagens, organização, espacialização e comportamento hidrossedimentológico podem conter informações sobre o passado e o presente do regime tectônico de uma região (KELLER; PINTER, 2002) e, de acordo com Schumm et al. (op. cit.), cada padrão de drenagem apresenta um significado litoestrutural.

Alguns parâmetros morfométricos podem ser aplicados com o intuito de auxiliar na caracterização, na quantificação e na fundamentação teórica sobre alterações ou anomalias, bem como no controle estrutural da rede de drenagem. Alguns desses parâmetros foram desenvolvidos em meados do século XX, entre os quais podemos destacar: Horton, (1945); Strahler, (1952); Howard, (1967); Hack, (1973); Burnett; Schumm, (1983) dentre outros.

Sendo a rede de drenagem o elemento mais sensível às alterações crustais, o entendimento do seu comportamento é importante para análises morfotectônicas e/ou morfoestruturais, pois constitui uma importante ferramenta dada a sua responsividade à alterações ou reativações tectônicas (COUTO, 2011).

Dessa forma, o presente artigo tem como objetivo aplicar três índices morfométricos: Índice de Relação Declividade-Extensão (RDE) (HACK, 1975), Fator de Assimetria da Bacia (FAB) (HARE; GARDNER, 1985) e Fator de Simetria Topográfica Transversal (FSTT) (HARE; GARDNER, 1985). Os resultados obtidos permitem o estabelecimento de correlação das informações com os dados morfoestruturais e morfotectônicos levantados por Manieri (2010). A análise correlativa possibilitou testar as aplicabilidades dessas metodologias nos estudos geomorfológicos e neotectônicos ${ }^{1}$.

\section{Área de estudo}

A bacia hidrográfica do ribeirão São Pedro encontrase localizada na região Norte Central do Estado do Paraná e abrange parcialmente os municípios de Faxinal e Cruzmaltina. Apresenta uma área de pouco mais de $140 \mathrm{~km}^{2}$, limitada entre as coordenadas $23^{\circ} 50^{\prime} 55^{\prime \prime}$ e $24^{\circ} 09^{\prime} 25^{\prime}$ ' Sul e $51^{\circ} 04^{\prime}$ $54^{\prime \prime}$ e $51^{\circ} 37^{\prime} 16^{\prime \prime}$ Oeste. Está inserida em um importante contexto geológico-geomorfológico de borda planáltica que divide o Terceiro do Segundo Planalto Paranaense, conforme classificação de Maack (1948). A bacia do ribeirão São Pedro é afluente da margem direita do rio Alonzo, ao longo de um curso de $46 \mathrm{~km}$ de extensão (Figura 1).

\section{Contexto Geológico e Geomorfológico local}

O relevo do Estado do Paraná está representado por uma sucessão de planaltos, formando uma sequência de patamares que inclinam suavemente para Oeste acompanhando o mergulho das formações geológicas da Bacia Sedimentar do Paraná. Além dos planaltos vinculados à Bacia Sedimentar do Paraná, ocorrem os planaltos e serras do Escudo Atlântico, localizados na parte Leste do estado. O limite desses planaltos é bem evidenciado pela presença de escarpas da Serra Geral, também denominada localmente de Serra do Cadeado e da Bufadeira.

As morfoestruturas da borda planáltica limítrofe do Segundo com o Terceiro Planalto paranaense encontram-se associadas a unidades litológicas aflorantes (Figura 2) e por estruturas tectônicas como falhas, juntas e diques. As zonas mais rebaixadas do relevo são dominadas principalmente por rochas pertencentes à Formação Rio do Rasto, composta de arenitos e argilitos do Permiano Superior. Gordon Jr (1947) propôs a subdivisão dessa Formação em dois Membros, o Membro Serrinha (base) formado em ambiente marinho raso e o Membro Morro Pelado (base) formado em ambiente fluvial.

\footnotetext{
${ }^{1}$ Neste artigo, o conceito de neotectônica utilizado é aquele proposto por Pavlides (1989), o qual a define como eventos novos que ocorreram ou estão ocorrendo numa região [...] após sua reorganização tectônica mais significativa.
} 


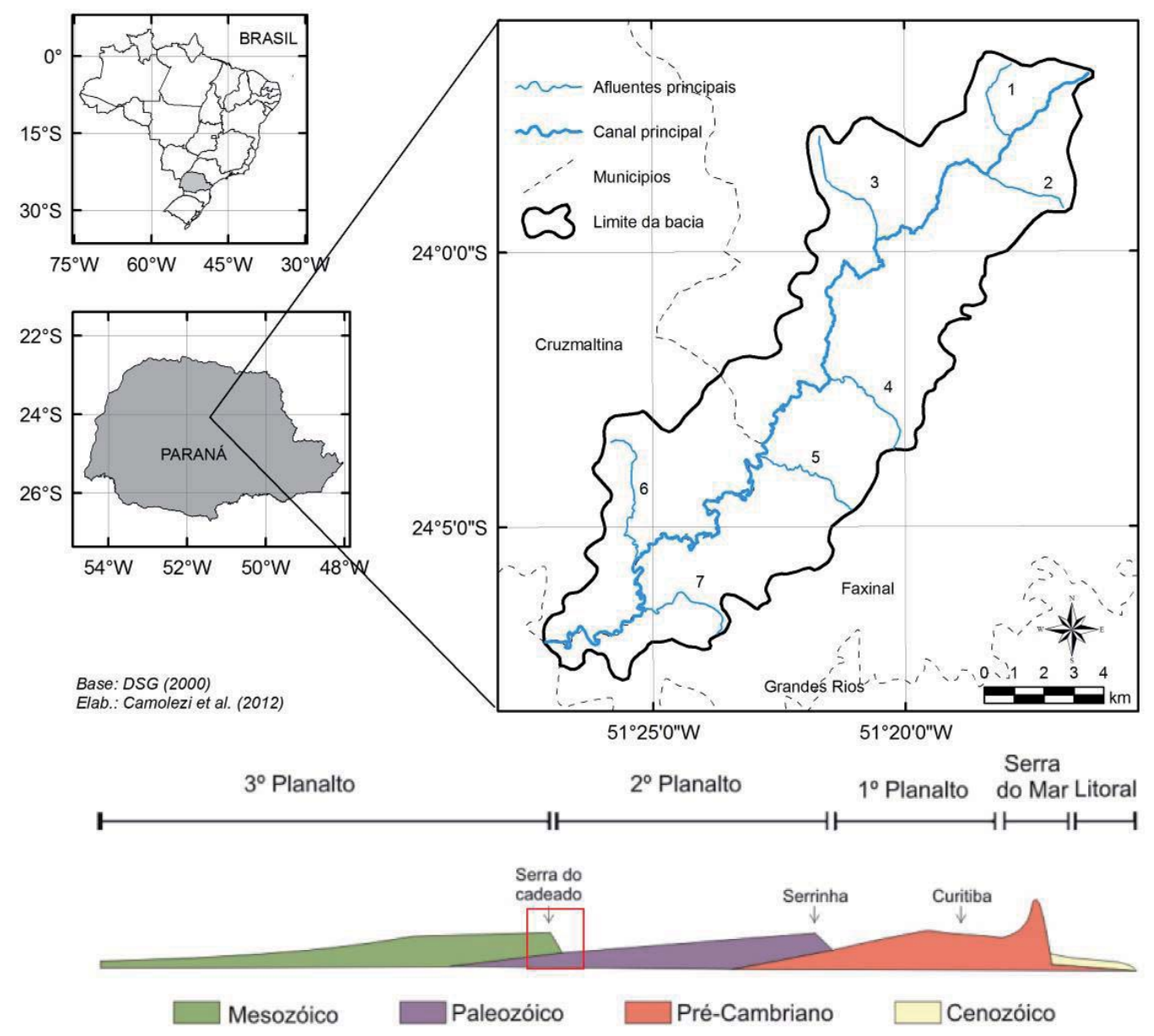

Figura 1 - Localização da área de estudo no Brasil e no Estado do Paraná em planta e em perfil topográfico esquemático.

\begin{tabular}{|c|c|c|c|}
\hline PER & GRUPO & \multicolumn{2}{|c|}{ FORMAÇÃO } \\
\hline & \multirow{3}{*}{ São Bento } & Serra Ceral & Mb. Nova Prata \\
\hline & & & Boncanu \\
\hline $\operatorname{Tr}$ & & & Prambeda \\
\hline P & Passa Dois & & Rio do Rasto \\
\hline
\end{tabular}

Figura 2 - Coluna estratigráfica da bacia do ribeirão São Pedro

A Formação Pirambóia ocorre sobreposta a Formação Rio do Rasto em contato discordante com suave angularidade (SOARES, 1973, 1975). É constituída por arenitos finos e siltosos, cinza claros e friáveis num pacote de cerca de $20 \mathrm{~m}$ de espessura. A Formação Pirambóia apresenta pouca expressão topográfica, seus arenitos mais friáveis podem formar cavidades no contato com a Formação Botucatu, constituíndo pequenas grutas.

A Formação Botucatu corresponde a arenitos vermelhos, quartzosos, finos e bem selecionados e com pouca matriz argilosa, num pacote de $50 \mathrm{~m}$ de espessura. A estratificação cruzada de médio a grande porte indica ambiente deposicional eólico. $\mathrm{Na}$ seção basal do arenito Botucatu, ocorre um pacote de $20 \mathrm{~m}$ de espessura, composto de arenitos médio a grossos, as vezes conglomeráticos, quartzosos amarelos ou vermelhos. Soares (1973) denominou de Fácies Torrencial esse pacote basal.

As litologias areníticas da Formação Botucatu apresentam grande expressão no relevo regional e local. Elas formam cornijas escarpadas e íngremes, associadas às Fácies Torrecial e Eólica, com desníveis de 20 a 50 metros. 
A Formação Serra Geral ocupa o topo da coluna estratigráfica na área estudada. Essa formação é constituída por basaltos e diabásios resultantes do vulcanismo fissural mesozoico. Os basaltos são negros, afaníticos ou equigranulares muito finos (STRUGALE et al., 2007). Essas litologias ocupam o terço superior da bacia hidrográfica do ribeirão São Pedro, formando uma plataforma de colinas baixa de topos e vertentes convexas. $\mathrm{Na}$ área de estudo, ocorre grande quantidade de corpos intrusivos injetados durante o magmatismo Serra Geral, representados por diques e soleiras de diabásio. Os diques apresentam grande expressão topográfica local e regional, especialmente junto às litogias pelíticas adjacentes, da Formação Rio do Rasto, nas quais a erosão diferencial permitiu a formação de serras alongadas de direção N40-50W.

Os depósitos cenozóicos constituem as formações superficiais que recobrem as formações paleozoicas e mesozoicas mencionadas acima. Os depósitos cenozóicos são caracterizados por materiais inconsolidados encontrados em diferentes contextos geomorfológicos e cuja gênese pode ser aluvial ou coluvial, associados a leques aluviais, depósitos de inundação, barras late- rais de canal e depósitos de encosta. Essas formações superficiais apresentam baixa coesão, pouca espessura e apresentam inclinação de acordo com o gradiente deposicional e a topografia do substrato.

- O Arco de Ponta Grossa é a flexura de relevância regional, de direção NW-SE, expressa segundo Zalán et al. (1990) por falhas profundas preenchidas por espessos diques de diabásio, alimentadores dos derrames que compõem a Formação Serra Geral.

A parte central do Arco de Ponta Grossa é limitada pelos lineamentos do rio Alonzo e de São JerônimoCuriúva. Nesse contexto estrutural, Strugale et al. (2007) propõem uma compartimentação morfotectônica da região da Serra do Cadeado, a partir de blocos tectônicos definidos como: bloco sudoeste, central e nordeste, limitados pelas zonas de falhas de Tamarana e rio Pereira, ambas de direção NW-SE (Figura 3). Segundo os referidos autores o bloco central corresponde à zona mais soerguida, com caimento para NE e SW. Nesse contexto, a bacia do ribeirão São Pedro encontra-se em posição periférica ao alto estrutural, que constitui regionalmente o bloco central segundo os autores supracitados.

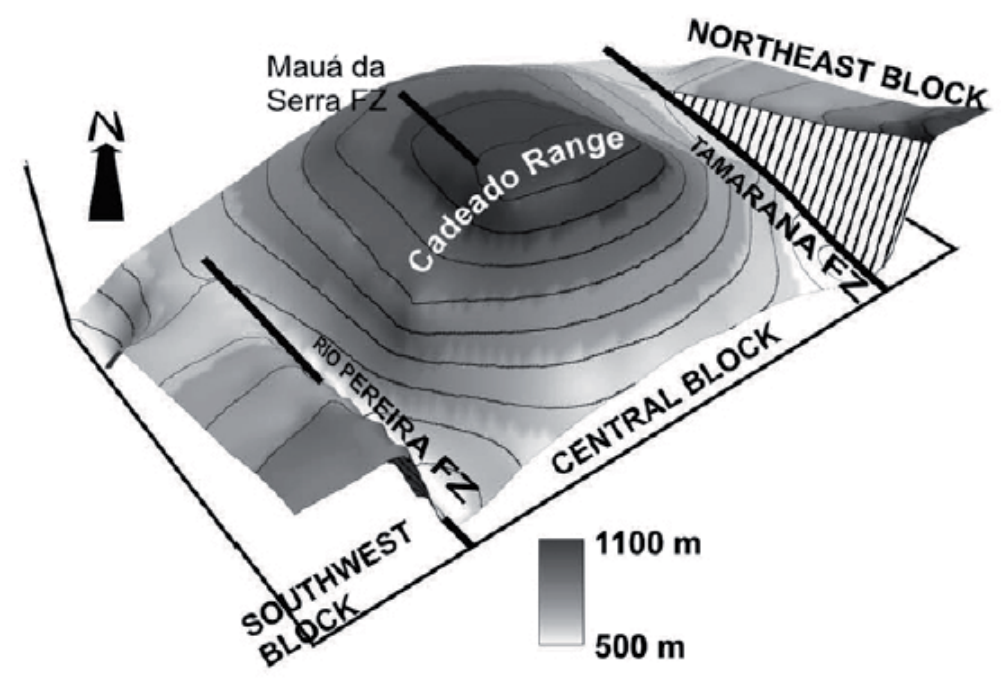

Figura 3 - Modelo de relevo idealizado mostrando a expressão atual devido à disposição dos blocos morfotectônicos. A área de estudo situa-se entre a zona de falhas de Mauá da Serra e a zona de falhas do rio Pereira.

Fonte: Adaptado de Strugale et al. (2007) 
A bacia do ribeirão São Pedro se desenvolve nesse contexto de borda planáltica, formando uma bacia alongada de direção NE-SW. Manieri (2010) propôs a divisão da bacia em compartimentos morfoestruturais definidos como: Compartimento Morfoestrutural da Cimeira Basáltica (CMCB), Compartimento Morfoestrutural das Superfícies Inumadas (CMSI) e o Compartimento Morfoestrutural das Superfícies Dissecadas (CMSD).

O CMCB é representado por colinas baixas, com vertentes e topos convexos, em altitudes entre 680 e $980 \mathrm{~m}$, e declividades inferiores $25 \%$. O substrato é representado por basaltos da Formação Serra Geral.

O CMSI encontra-se junto à porção mediana da bacia, sendo sua principal característica as amplas escarpas erosivas e estruturais com desnível de até $130 \mathrm{~m}$, que se alternam sob influência de diques de diabásio. No limite com o CMCB, as escarpas são limitadas por falhas normais com cornijas basálticas sobrepostas a arenitos da Formação Botucatu. Este último podendo formar patamares estruturais e ressaltos litológicos.

Os topos da margem direita da bacia são escarpas controladas pela reologia das rochas ígneas e morfologia do Arco de Ponta Grossa, essa disposição favoreceu os processos erosivos que resultam em elevações alinhadas NW-SE e E-W. A maior parte do CMSI corresponde a amplo vale dissecado sobre rochas da Formação Rio do Rasto, formando uma superfície com colinas baixas, com altitudes entre $600 \mathrm{e}$ $720 \mathrm{~m}$, com alta densidade de fraturas. As vertentes possuem alta declividade, variando de cerca de $8 \%$, nos fundos de vale a mais de $90 \%$ junto às escarpas.

O CMSD é o compartimento do baixo curso, cujas declividades são inferiores a $8 \%$. As colinas são baixas com topos planos, em altitudes de menos de $380 \mathrm{~m}$. Nesse compartimento, a planície de inundação torna-se mais ampla.

\section{Fundamentação Teórico-Metodológica}

Aplicadas à identificação de anomalias de drenagens, alguns métodos vêm sendo difundidos como o índice de Relação Declividade-Extensão (HACK, 1973), fator de assimetria de bacias (HARE; GARDNER, 1985) e fator de simetria topográfico transversal (HARE; GARDNER, op. cit.), todos utilizados neste trabalho. Após aplicação das metodologias supracitadas, procedeu-se a análise dos resultados com base nos dados morfoestruturais da área, levantados e sistematizados por Manieri (2010).

O índice proposto por Hack (1973), denominado de RDE é uma ferramenta importante para detecção de anomalias na concavidade natural do perfil longitudinal de canais fluviais, que possibilita a normalização dos valores de gradiente e a identificação de anomalias de drenagem em cada trecho do seu curso (FUJITA, 2009). O índice RDE pode ser obtido através das seguintes fórmulas:

\section{RDE total $=(\Delta H / \log L) ;$ RDE trecho $=(\Delta H / \Delta L) \times L$}

Onde: $\Delta \mathrm{H}$ é igual à diferença altimétrica entre os extremos do canal ou do trecho selecionado, log é o logaritmo natural, L é a extensão total do curso d'água e $\Delta$ L é a extensão do trecho selecionado (Figura 4).

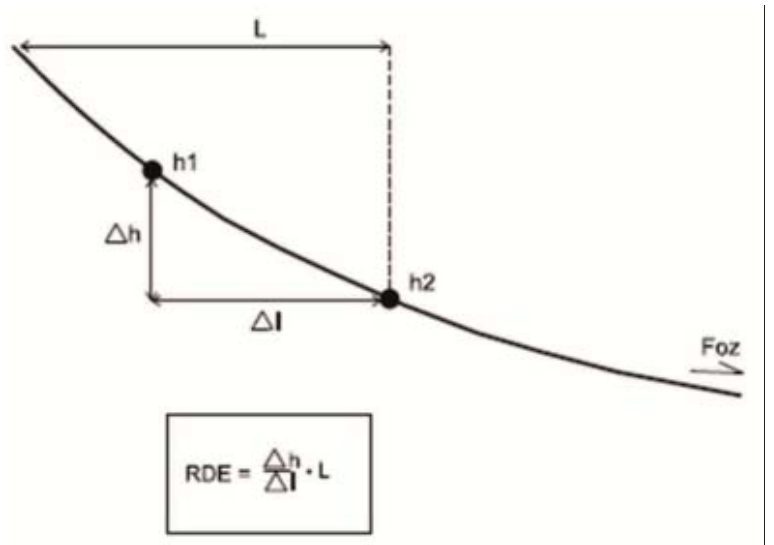

Figura 4 - Parâmetros utilizados para cálculo do RDE em segmentos de drenagem

Fonte: Etchebehere (2004)

Os setores anômalos são definidos a partir de limiares (SEEBER; GORNITZ, 1983 apud ANDRADES FILHO, 2010), onde se considera RDEs/RDEt $=2$ como o limiar inferior da faixa de anomalias, $\geq 2 \mathrm{e}<10$ como anomalias de $2^{\mathrm{a}}$ ordem e $\geq 10$ como anomalias de $1^{\mathrm{a}}$ ordem .

$\mathrm{O}$ fator de assimetria de bacias, proposto por Hare; Gardner (1985) indica que a assimetria de uma bacia reflete o deslocamento lateral do seu canal principal, perpendicularmente à direção do seu eixo (Figura 5a). O método consiste na divisão entre a área da margem direita de uma bacia pela área total da mesma, como se pode observar na seguinte fórmula:

$\mathrm{FAB}=100 \times(\mathrm{Ra} / \mathrm{Ta})$

Onde:

$\mathrm{Ra}=$ área localizada à margem direita da bacia; $\mathrm{Ta}=$ área total da bacia.

De acordo com Hare; Gardner (1985), quando o valor encontrado for próximo a 50, isso indica que não houve basculamento significativo e a bacia se encontra em condições estáveis. Valores menores que 50 apontam para um possível basculamento da margem esquerda da bacia, enquanto valores maiores do que 50 indicam um provável basculamento da margem direita da bacia.

Hare; Gardner (1985) propuseram o fator de simetria topográfica transversal (FSTT), que traz uma relação entre a distância da linha média da bacia e o canal principal e a distância entre a linha média da bacia e o seu divisor mais próximo (Figura 5b). Essa relação indica o qual deslocado o canal está do centro da bacia. 


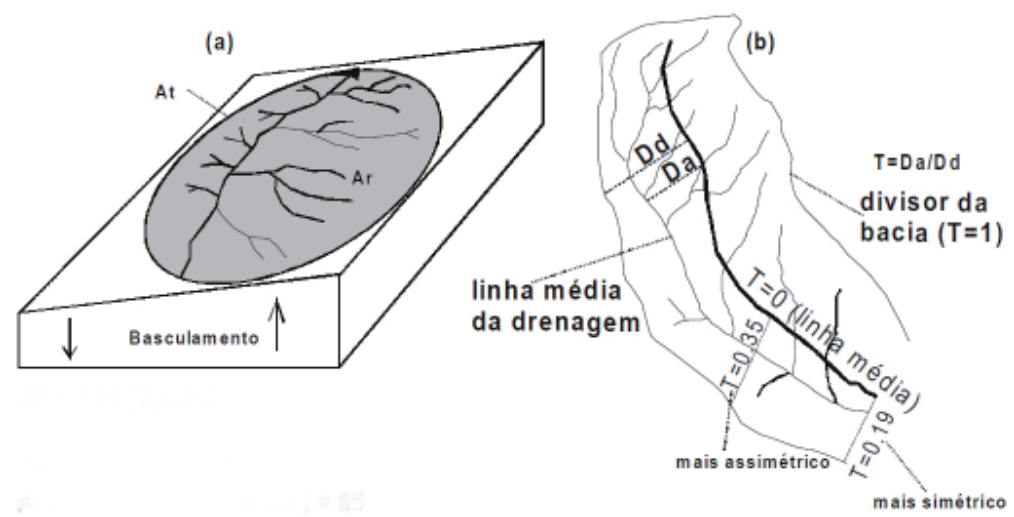

Figura 5 - Variáveis utilizadas para cálculo do fator de assimetria da bacia (a) e fator de simetria topográfica transversal (b).

Fonte: Adaptado de Salamuni et al. (2004)

A fórmula utilizada para o cálculo do FSTT é a que segue:

\section{$\mathrm{T}=\mathrm{Da} / \mathrm{Dd}$}

Onde: $\mathrm{Da}=$ corresponde à distância da linha média do eixo da bacia de drenagem até a linha média do cinturão do meandro ativo; $\mathrm{Dd}=$ a distância da linha média da bacia até o divisor da bacia.

Quanto mais próximo de 0 for o resultado, maior é a simetria topográfica transversal e quanto mais próximo de 1 , menor a simetria.

Foram utilizados para a elaboração deste trabalho as cartas topográficas de Faxinal e de Rio Bom, ambas na escala de 1:50.000 (DSG, 2000a,b). Também se utilizou do mapa morfoestrutural da bacia do ribeirão São Pedro (MANIERI, 2010), elaborado com base em fotografias aéreas do ITCG (Instituto de Terras, Cartografia e Geociências), com escala de 1:25.000, da década de 1980, imagens de radar do projeto TOPODATA (VALERIANO, 2005) e dados coletados em campo. As coordenadas utilizadas são plano-retangulares (UTM) e o sistema de referência utilizado foi o SAD69.

Os dados das cartas topográficas de Faxinal e de Rio Bom foram inseridos em softwares de informação geográfica e processados para que os resultados fossem espacializados. O SIG ArcGIS ${ }^{\circledR}$ v.9.2 foi utilizado para mensurar distâncias, processar arquivos vetoriais e realizar a edição final das cartas apresentadas. O software Grapher ${ }^{\circledR}$ v.8 foi utilizado para realizar os cálculos dos índices de RDE, FAB e FSTT e gerar seus gráficos. Além dos dois softwares mencionados, utilizou-se também o software Surfer $^{\circledR}$ V.8 para interpolação dos resultados do índice RDE.

Para o cálculo do índice RDE considerou-se o trecho as áreas localizadas entre cotas topográficas (equidistância de $20 \mathrm{~m}$ ). Na etapa de geração dos gráficos, o software Gra$\operatorname{pher}^{\mathbb{B}}$ v.8 calculou a linha de melhor ajuste dos canais, necessário para saber se os trechos encontram-se em ascensão, subsidência ou equilíbrio, considerando-se um desajuste de $10 \mathrm{~m}$. O FSTT foi calculado a partir da geração de 26 linhas perpendiculares aos eixos da bacia e, a partir do seu ponto médio, foi traçada a linha média da bacia.

\section{Resultados e Discussões}

O índice de Relação Declividade Extensão foi calculado para o canal principal da bacia do ribeirão São Pedro e para sete afluentes (Figura 1). Os resultados foram plotados em gráficos e em um mapa de isolinhas. $\mathrm{O}$ canal principal da área de estudo foi dividido em 31 trechos, dos quais 13 apresentaram-se em equilíbrio, 9 com anomalias de segunda ordem e 9 com anomalias de primeira ordem. Os trechos em equilíbrio estão localizados próximos às nascentes e próximos da foz do ribeirão São Pedro, enquanto que os trechos com anomalias de segunda ordem se distribuem do alto ao baixo curso do ribeirão São Pedro.

Os trechos que apresentaram maiores índices de anomalia foram aqueles localizados entre as cotas de 720 e 560 metros, perfazendo uma extensão total de 1231,12 metros. Esses trechos apresentaram os seguintes valores: Cota 720-700 - 82,76; Cota 700-680 - 38,65; Cota 680-660 - 78,66; Cota 660-640-101,56; Cota 640-620 - 71,47; Cota 620-600 - 69,01; Cota 600-580 16,93 e Cota 580-560 - 11,45 (Figura 7).

O perfil longitudinal do canal principal (Figura 6) apresentou dois comportamentos distintos. Em ambos os casos, o perfil longitudinal apresenta-se com um desajuste de aproximadamente $100 \mathrm{~m}$ em relação à linha de melhor ajuste, porém, no primeiro caso, o perfil apresenta-se em forma convexa e no segundo, em forma côncava, indicando probabilidade de trechos em ascensão e em subsidência, respectivamente.

Dos sete afluentes escolhidos para o cálculo do RDE, todos apresentaram trechos em equilíbrio e trechos com anomalias de segunda ordem sendo que apenas três apresentaram trechos com anomalias de primeira ordem. 
A interpolação dos resultados de RDE (Figura 7) mostrou que a área com maiores índices de anomalia de primeira ordem está localizada na porção Oeste da bacia, próximo ao médio cur- so. Já as áreas de anomalias de segunda ordem ocorrem por toda a extensão da área de estudo. As áreas em que ocorrem trechos em equilíbrio estão mais ao Norte da bacia e no baixo curso.
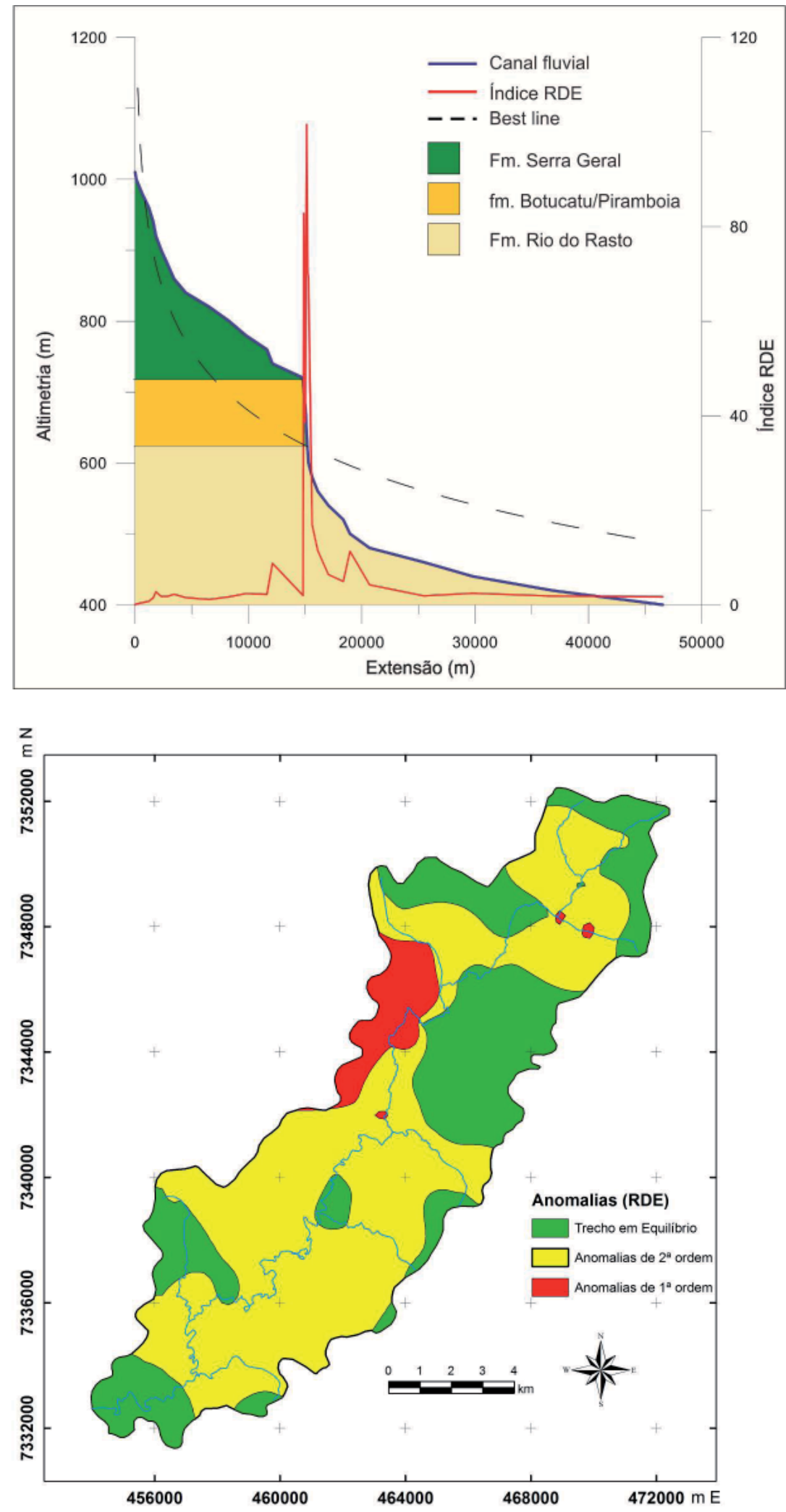

Figura 7 - Distribuição das anomalias com base na aplicação do indice $R D E$

Figura 6: Perfil longitudinal do ribeirão São Pedro com valores de anomalia para o canal. Verificar desajustes do perfil longitudinal com a linha de melhor ajuste (best line). 
O fator de simetria topográfica transversal (FSTT) foi calculado com base em 26 perfis transversais a área de estudo e, a partir desses, calculada a linha média do eixo da bacia. $\mathrm{O}$ valor médio encontrado para a área de estudo foi de 0,25 , enquanto que em algumas áreas esse valor chegou a 0,89 . A figura 8 apresenta a bacia com seu eixo médio e o canal principal, os perfis transversais e o resultado do FSTT para cada perfil.

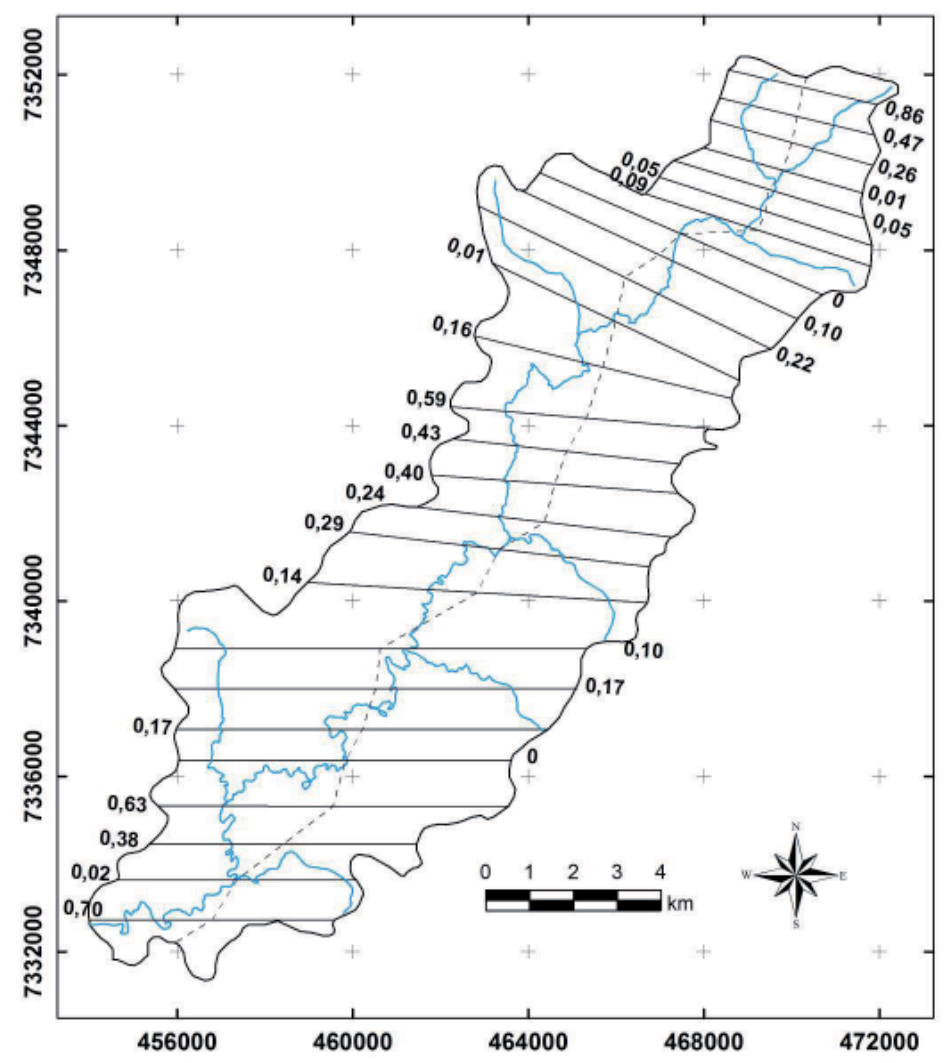

Figura 8 - Fator de simetria topográfica transversal da área de estudo. A linha tracejada representa o eixo central da bacia.

De acordo com Salamuni (2004), a assimetria de uma bacia reflete o componente de deslocamento lateral do rio principal, perpendicular à direção do seu eixo, sendo que essa migração pode ser causada por processos fluviais internos e/ ou forças tectônicas. Para a bacia do ribeirão São Pedro, o fator de assimetria de bacia (FAB) resultou num valor 44 . Este valor pode revelar um provável basculamento para a margem direita da bacia, em pequena magnitude (valor próximo a 50), que pode ter proporcionado um deslocamento do canal principal, como verificado na figura 8 .

Percebe-se que os valores mais altos de FSTT estão deslocados para a margem direita da bacia no médio e baixo curso, sendo que apenas no alto curso é que o canal esta deslocado para a margem esquerda da bacia.

O índice RDE e o fator de simetria topográfica transversal (FSTT) apresentaram resultados semelhantes, visto que a área onde houve maior ocorrência de anomalias de primeira ordem (Figura 7) é a mesma em que ocorrem os maiores resultados de deslocamento do canal segundo o FSTT, deslocamento este que dá suporte aos resultados obtidos utilizando o FAB.

Os dados morfométricos de anomalias, tanto pelo Índice de RDE (Figuras 6 e 7) quanto pelos índices de FSTT (Figura 8), permitem estabelecer uma análise correlativa com os dados morfoestruturais levantados por Manieri (2010). As maiores anomalias de RDE (entre 70 e 100), correspondem à zona limítrofe dos compartimentos CMCB e CMSI, que se destacam por escarpas estruturais e erosivas (Figura 9, com destaque na Figura 10). Nessa área, ocorre a mais alta densidade de lineamentos de toda bacia, com direções predominantes N40-60W, conforme Manieri (2010), que é concordante com a disposição geral da escarpa e discordante do sentido geral da bacia. 
O deslocamento da escarpa, por falhas normais, conforme sugerido por Manieri (2010) evidencia a presença de um bloco alto que corresponde ao $\mathrm{CMCB}$ e um bloco baixo junto ao CMSI, concordante com os índices de RDE.

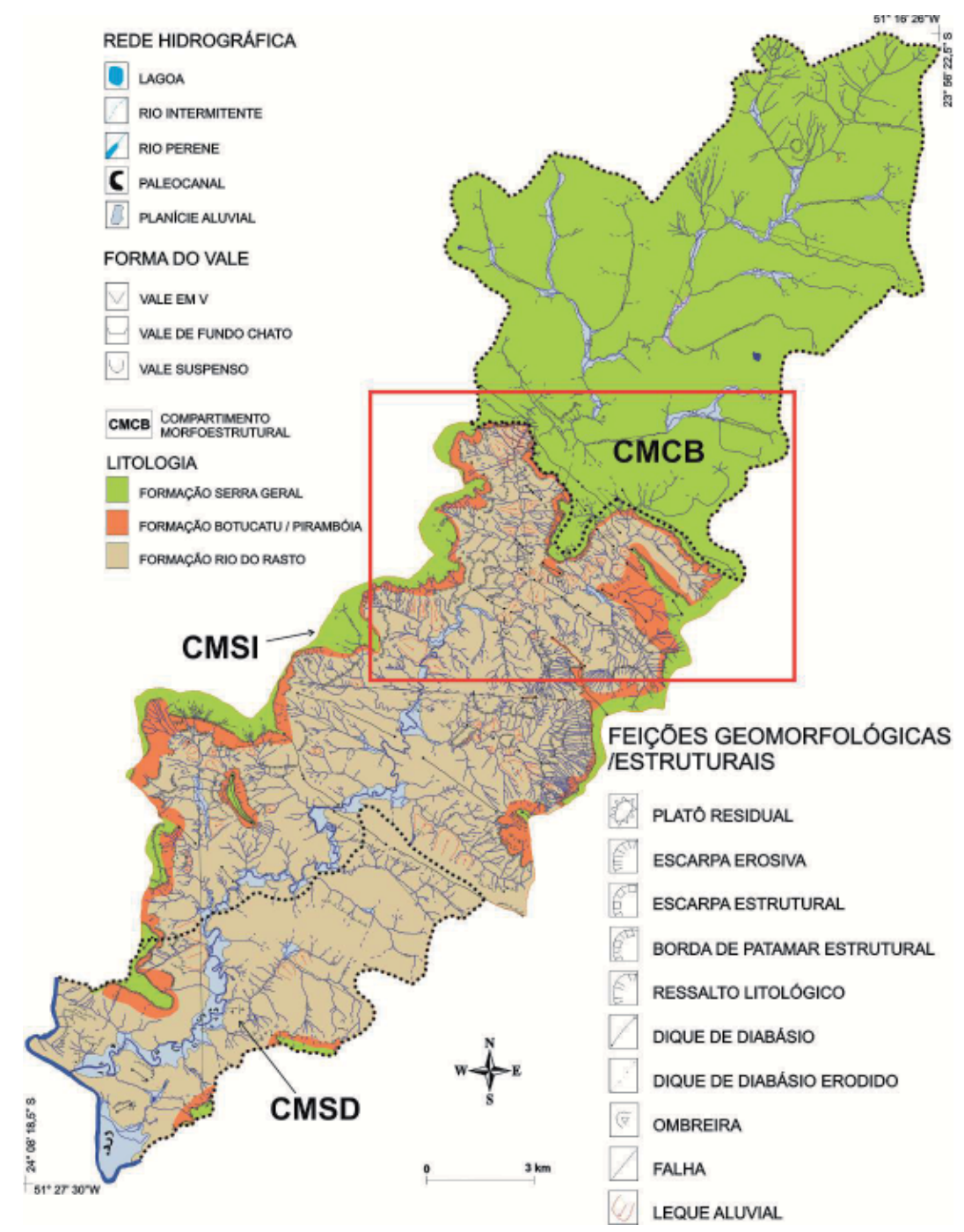

Figura 9: Mapa morfoestrutural da bacia do ribeirão São Pedro. A área em destaque (quadrado vermelho) é destacada na Figura 10. Fonte: Adaptado de Manieri (2010)

Os índices de RDE evidenciaram ainda fortes anomalias junto à zona limítrofe do CMCB e CMSI, formando uma faixa alongada de anomalias de $1^{\mathrm{a}}$ ordem, concentradas na parte Oeste da bacia. Convém destacar, que a mais ampla zona em equilíbrio dentro da bacia, encontra-se na margem oposta. Essa zona em equilíbrio corresponde à área de maior densidade de drenagem da bacia, onde os interflúvios encontram-se mais arrasados.

Considerando-se que nesse trecho o canal encontra-se deslocado para oeste, formando um vale estreito e profundo, conhecido localmente pelo Salto São Pedro, indicando um basculamento para oeste, concordante, portanto, com a posição do canal nesse trecho.
As zonas de menor índice FAB e FSTT, junto ao alto curso (CMCB), podem ser explicadas pela resistência litológica das rochas ígneas e disposição horizontal dos derrames, com ligeiro aumento das anomalias junto aos cursos fluviais desse compartimento geomorfológico.

Outro importante segmento em equilíbrio refere-se ao CMSD, cujas litologias pelíticas da formação Rio do Rasto, impõem resistência à erosão de forma mais limitada, quando comparado aos outros compartimentos geomorfológicos.

Embora seja evidente a influência tectônica no desenvolvimento dos compartimentos geomorfológicos descritos por Manieri (2010), não se pode descartar a influência da 
erosão diferencial nesse processo. A presença e a disposição dos diques de diabásio, cuja resistência litológica é maior que as litologias areníticas e pelíticas das áreas vicinais torna complexa a explicação pelo simples basculamento da região. Fortes et al. (2010) e Couto et al. (2012) com base em mapas de Nivelamento de Topos, realizado para a carta de Faxinal, na escala de 1:50.000, identificaram na bacia do ribeirão São Pedro forte influência da erosão diferencial no recuo e da rotação da escarpa de E-W para NW-SE, esta, coincidente com a direção geral dos diques de diabásio.

Apesar da difícil compreensão do arranjo dos blocos tectônicos e das relações cinemáticas, a partir da ánalise correlativa da morfometria com a morfoestrutura, fica evidente a importância dos índices de anomalias como indicador de atividade tectônica, mesmo com a presença da erosão diferencial.

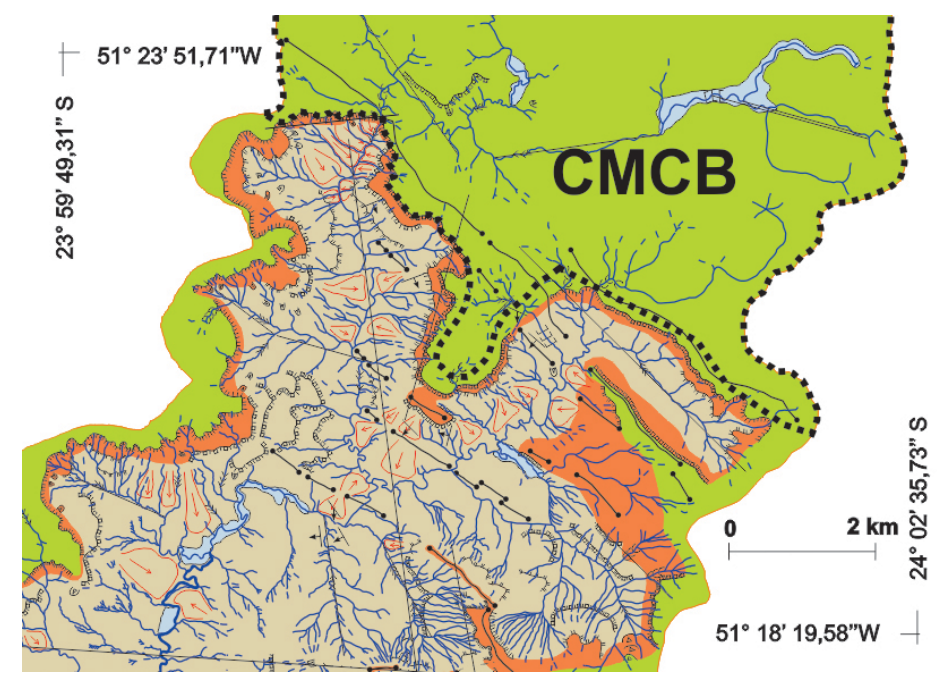

Figura 10 - Destaque do mapa morfoestrutural para a área de maior ocorrência de anomalias.

A legenda é a mesma adotada para a Figura 9.

Fonte: Adaptado de Manieri (2010)

\section{Considerações Finais}

A aplicação das três metodologias utilizadas (índice de Relação Declividade-Extensão, Fator de Assimetria de Bacias e Fator de Simetria Topográfica Transversal) foi importante, pois seus resultados apresentaram relação entre si.

A presença das anomalias verificadas pelos índices mencionados acima corroboraram com os dados presentes no mapa morfoestrutural de Manieri (2010), mostrando, dessa forma, a eficiência dos métodos propostos.

Tanto os índices aplicados neste trabalho quanto os dados de comportamento morfoestrutural revelaram controle estrutural da rede de drenagem, com presença de anomalias significativas ao longo da bacia do ribeirão São Pedro.

Embora os dados de assimetria da bacia tenham corroborado com as análises morfoestruturais e morfotectônicas de Manieri (2010), não se pode descartar a importância dos elementos litoestruturais nos processos de erosão diferencial dos compartimentos geomorfológicos.

\section{Referências Bibliográficas}

ANDRADES FILHO, C. O. Análise morfoestrutural da porção central da Bacia Paraíba (PB) a partir de dados MDE-SRTM e ALOS-PALSAR FBD. 177 f. 2010. Dissertação (Mestrado em Sensoriamento Remoto). Instituto Nacional de Pesquisas Espaciais, Ribeirão Preto. 2010.

BURNETT, A. W.; SCHUMM, S. A. Alluvial river response to neotectonic deformation in Louisiana and Mississippi. Science, v. 222, p. 49-50, 1983.

COUTO, E. Influência morfotectônica e morfoestrutural na evolução das drenagens nas bordas planálticas do Alto IvaíRio Alonzo - Sul do Brasil. 123 f. 2011. Dissertação (Mestrado em Geografia). Programa de Pós-Graduação em Geografia, Universidade Estadual de Maringá, Maringá, Paraná, Brasil.

; FORTES, E.; SORDI, M. V.; MARQUES, A. J.; CAMOLEZI, B. A. Seppômen maps for geomorphic developments analysis: the case of Paraná plateau border, Faxinal, State of Paraná, Brazil. Acta Scientiarum. Technology, v. 34, p. 71-78, 2012.

DSG - Departamento de Serviço Geográfico. Carta topográfica de Faxinal-S. Folha SF-22-V-B-III-1. Escala 1:50.000, 2000a. 
Carta topográfica de Rio Bom. Folha SF-22-Y-D-VIIII. Escala 1:50.000, 2000b.

ETCHEBEHERE, M. L. C., Terraços neo-quaternários no vale do rio do Peixe, planalto ocidental paulista: Implicações estratigráficas e tectônicas. Rio Claro, 2000. 2 v. Tese (Doutorado em Geociências) - Instituto de Geociências e Ciências Exatas, Universidade Estadual Paulista.

; SAAD, A. R.; CASADO, F. C. Análise Morfoestrutural Aplicada no Vale do Rio do Peixe (SP): Uma Contribuição ao Estudo da Neotectônica e da Morfogênese do Planalto Ocidental Paulista. Geociências, Guarulhos, v.10, n. 6, 2004, 45-62.

FORTES, E.; COUTO, E. V.; SORDI, M. V.; MARQUES, A. J. EVOLUÇÃO GEOMORFOLÓGICADA ÁREAABRANGIDA PELA CARTA DE FAXINAL (PR), COM BASE EM MAPAS DE NIVELAMENTOS DE TOPOS. In: SANTIL, F. L. P.; SILVEIRA, H.; SOUZA, M. L.; SANTOS, F. R. (Orgs.). Recursos Tecnológicos Aplicados a Cartografia. 1 ed. Maringá: Sthampa Gráfica e Editora, v. 1, p. 100-113. 2010.

FUJITA, R. H. O perfil longitudinal do rio Ivaí e sua relação com a dinâmica de fluxos. 118 f. 2009. Dissertação (Mestrado em Geografia). Programa de Pós-Graduação em Geografia, Universidade Estadual de Maringá, Maringá, Paraná, Brasil.

GORDON JR. M. Classificação das formações gondwânicas do Paraná, Santa Catarina e Rio Grande do Sul. Notas Preliminares e Estudos, DNPM/DGM, Rio de Janeiro, n. 38, p.1-20, 1947.

HACK, J.T. Stream-profile analysis and stream-gradient index. U.S. Geol. Survey, Jour. Research, 1(4): 421-429, 1973.

HARE P. W.; GARDNER I. W. Geomorphic indicators of vertical neotectonism along converging plate margins. Nicoya Peninsula, Costa Rica. In: MORISAWA M.; HACK J. T. (eds.). Tectonic Geomorphology. Proceedings of $15^{\text {th }}$ Annual Binghamton Geomorphology Symposium. 1985

HORTON, R. E. Erosional development of streams and their drainage basins: hydrophysical approach to quantitative morphology. Geological Society of America Bulletin, v. 56, p. 275-370, 1945.

HOWARD, A. D. Drainage analysis in geologic interpretation: A summary. AAPG Bulletin, v. 51, p. 2246-2259, 1967.

IBGE, Instituto Brasileiro de Geografia e Estatística. Manual técnico de Geomorfologia. (coord.) NUNES, B. A; RIBEIRO, M. I. C.; ALMEIDA, V. J.; NATALI FILHO, T. Série Manuais Técnicos em Geomorfologia, 5. Rio de Janeiro, 112 p., 1995.

KELLER, E. A.; PINTER, N. Active Tectonics, Englewood Cliffs, NJ: Prentice Hall. 2002.

MAACK, R. Notas preliminares sobre clima, solos e vegetação do Estado do Paraná. Arquivos de Biologia e Tecnologia, Curitiba, v. 2, pp.102-200, 1948.

MANIERI, D. D. Comportamento Morfoestrutural e Dinâmica das Formas do Relevo da Bacia Hidrográfica do Rio São Pedro, Faxinal - PR. 103 f. Dissertação (Mestrado em Geografia) Programa de Pós-Graduação em Geografia, Universidade Estadual de Maringá, Maringá, Paraná, Brasil. 2010 .
MINEROPAR - Minerais do Paraná S/A. Mapa geológico do Estado do Paraná, escala 1:1.000.000 (meio digital). Curitiba, CD-ROM. 2002

PAVLIDES, L. Early Paleozoic composite melange terrane, central Appalachian Piedmont, Virginia and Maryland: its origin and tectonic history. In: Horton, J. W., Jr.; Rast, N.; ed., Melanges and olistostromes of the United States Appalachians: Geological Society of America Special Paper, pp. 135-193. 1989.

SALAMUNI, E.; EBERT, H. D.; HASUI, Y. Morfotectônica da Bacia Sedimentar de Curitiba. Revista Brasileira de Geociências. Sociedade brasileira de Geologia - SBG, v. 34, n. 4, 469-478 pp. 2004.

SCHUMM, S. A. River response to baselevel change: Implications for sequence stratigraphy. Journal of Geology, v. 101, p. 279-294, 1993.

; DUMONT, J. F.; HOLBROOK, J. M. Active tectonics and alluvial Rivers. Cambridge University Press, Cambridge, 401 p. 2000.

SOARES, P. C. O Mesozoico gonduânico no Estado de São Paulo. 152 f. 1973. Tese (Doutorado em Geociências e Meio Ambiente). Universidade Estadual Paulista Júlio de Mesquita Filho, 1973.

Divisão Estratigráfica do Mesozoico no Estado de São Paulo. Revista Brasileira de Geociências, v. 5 p.229-251, 1975.

STRAHLER, A. N. Dynamic basis of geomorphology. Geological Society of American Bulletin, v. 63, p. 923-938, 1952.

STRUGALE, M.; ROSTIROLLA, S. P.; MANCINI, F.; PORTELA FILHO, C. V. Compartimentação Estrutural das Formações Pirambóia e Botucatu na Região de São Jerônimo da Serra, Estado do Paraná. Rev. Bras. de Geociências, vol. 34, p.303-316, 2004.

; FERREIRA, F. J. F.; FREITAS, R. C. Structural framework and Mesozoic-Cenozoic evolution of Ponta Grossa Arch, Paraná Basin, southern Brazil. Journal of South American Earth Sciences, v. 24, issues 2-4, 203-227, 2007.

VALERIANO, M. M. Modelo digital de variáveis morfométricas com dados SRTM para o território nacional: o projeto TOPODATA. In: XII SIMPÓSIO BRASILEIRO DE SENSORIAMENTO REMOTO, 2005, Goiânia. Anais... São José dos Campos: INPE, 2005, p. 3595-3602. CD-ROM, On-line. ISBN 85-1700018-8. Disponível em: http://marte.dpi.inpe.br/col/ltid.inpe. br/sbsr/2004/10.29.11.41/doc/3595.pdf. Acesso em outubro de 2011.

ZALÁN, P. V.; WOLFF, S.; CONCEIÇÃO, J. C. de J.; MARQUES, A.; ASTOLFI, M. A. M.; VIEIRA, I. S.; APPI, V. T.; ZANOTTO, O. A. Bacia do Paraná. In: RAJA GABAGLIA, G. P.; MILANI, E. J. (Coords.) Origem e Evolução de Bacias Sedimentares. PETROBRÁS, Rio de Janeiro, pp. 135-168, 1990. 